\title{
INHALATORY ANESTHESIA WITH LARYNGEAL MASK IN A BRUSHWOOD DOG (Cerdocyon thous)
}

\author{
VILANI, R.G.D'O.C. ${ }^{1}$; ROSA, D.B.S. ${ }^{2}$; SAMONEK, J.F.V. ${ }^{2}$ \\ ${ }^{1}$ Pontifícia Universidade Católica do Paraná; \\ ${ }^{2}$ Graduando PUC-PR.
}

A $4,9 \mathrm{~kg}$ adult female brushwood dog (Cerdocyon thous) from the Centro de Triagem de Animais Silvestres - Vivat Floresta - from the Pontifícia Universidade Católica do Paraná, was submitted to inhalatory anesthesia with laryngeal mask for a lip corrective surgery due to trauma. The laryngeal mask is a recent instrument in Veterinary Anesthesiology. It maintains the permeability of the patient's air tract ducts. Its use is simpler when compared with the endotracheal tube due to uncomplicated insertion and no possibility of trauma. Also, since laryngoscopy is not needed there is no provocartion of the vagus nerve stimulation. When compared to facial mask the laryngeal mask displays a larger safety enabling an effective assisted ventilation. The patient was captured by net and suffered anesthetic induction with the association of $70 \mathrm{mg}$ of ketamine hydrochloride and $6 \mathrm{mg}$ of diazepam, intramuscularly. After fifteen minutes the animal remained in a lateral recumbence with shallow and eyelid reflexes. The anesthetic complementation was then need with halothane inhalation via facial mask during two minutes, when abolition of protective reflexes and appropriate muscle relaxation was observed. A not inflated 2,0 laryngeal mask was then inserted and connected to a semi-closed circuit of inhalatory anesthesia for halothane administration. The vital signs of the patient were periodically measured through respiratory and heart rates and internal temperature. The inhalatory anesthesia lasted 60 minutes with excellent analgesia and myorelaxation. The laryngeal mask was removed 15 minutes after finished the anesthetic administration, simultaneously to the recovery of the patient. The use of the laryngeal mask was simple and practical and allowed safety and efficiency to the anesthetic act. It introduces an excellent option to the permeability air tract ducts maintenance in this specie.

Key Words: laryngeal mask, permeability, Cerdocyon thous, inhalatory anesthesia. 
